$\underline{170}$

\title{
La comunicación como comportamiento y acto expresivo
}

\author{
Vivian Romeu ${ }^{1}$ \\ Universidad Iberoamericana Ciudad de México
}

\section{RESUMEN}

La comunicación como comportamiento y acto expresivo constituye una nueva manera de entender y analizar los fenómenos comunicativos. El propósito de este trabajo es desarrollar una propuesta epistémico-conceptual alrededor de esta tesis y enfatizar su pertinencia para el campo de estudios sobre la comunicación. Para ello partimos del enfoque de la fenomenología de la percepción y nos apoyamos en los trabajos recientes de la biosemiótica, el enactismo y la neurobiología. Como parte de los resultados se desarrollan criterios e indicadores que definen los fenómenos comunicativos como actos y comportamientos expresivos, al tiempo que ofrece claves para su análisis.

Palabras clave: comunicación, expresión, comportamiento, fenómeno, biología

\begin{abstract}
Communication as behavior and expressive act is a new way of understanding and analyzing communicative phenomena. The purpose of this paper is to develop an epistemic-conceptual proposal around this thesis and to emphasize its pertinence for the field of studies on communication. For this we start from the perspective of the phenomenology of perception and rely on the recent work of biosemiotics, enactism and neurobiology. As part of the results, we develop criteria and indicators that define communicative phenomena as expressive acts and behaviors, while offering keys for their analysis.
\end{abstract} 1Doctora en Comunicación por la Universidad de La Habana. Actualmente es profesora-investigadora de la
Universidad Iberoamericana y coordinadora editorial de la Revista Iberoamericana de Comunicación. Miembro del
Sistema Nacional de Investigadores, nivel II; de la Red Internacional de Investigadores sobre la Frontera (RIIF); de la
Asociación Mexicana de Investigadores en Comunicación (AMIC) y de la Asociación Latinoamericana de Estudios
sobre el Discurso (ALED). Áreas de investigación: epistemología de la comunicación; comunicación y evolución;
comunicación, arte y estética; interculturalidad; representaciones sociales; semiótica y análisis del discurso. Ha pu-
blicado libros y artículos académicos en revistas nacionales e internacionales. Correo electrónico:
vromeu.romeu@gmail.com 
Key words: communication, expression, behavior, phenomenon, biology 


\section{INTRODUCCIÓN}

Comprender la comunicación como un comportamiento implica circunscribir la reflexión e investigación de la comunicación al interior de un programa más amplio de análisis del que hasta el momento se desarrolla en el campo académico de los estudios sobre la comunicación. Esto constituye una necesidad, además, dada la fragmentación conceptual y teórica que nos caracteriza como campo, de manera que encontrar un nicho epistémico para comprender en su totalidad lo que la comunicación es, indica en la práctica dotar a la comunicación de un anclaje desde el que pensar su ocurrencia y funcionamiento a partir de un tronco común sólido y general.

Si lo miramos desde esta perspectiva, por sólo poner un ejemplo, el cambio civilizatorio que proponen los enfoques que están en contra del especismo, como el veganismo y el vegetarianismo, posibilita entenderlos como cuerpos de conocimiento y acción en función de la transformación de nuestros hábitos alimenticios, lo que puede conceptualizarse sin dudas como formas de comportamiento del ser humano en el siglo XXI, las cuales, junto a muchos otros casos típicos de nuestra vida actual, son reveladoras del sentir y el pensar del ser humano contemporáneo.

\section{Vivian Romeu}

Dichos comportamientos se fraguan comunicativamente como parte del amplio y diversificado espectro de "decir" de los humanos hoy en día, mismo que se ha ido configurando evolutivamente a través de formas y medios cada vez más complejos a lo largo del tiempo, para responder a los imperativos de la gestión de la vida humana en sociedad. Esto, por supuesto, define la comunicación como una estrategia de sobrevivencia y adaptación del ser humano que, vista desde esta perspectiva, hemos de admitir que ha existido desde siempre, aunque en cada época y en función de las capacidades expresivas de cada ser que la ejecute, se distinga por tipos, naturaleza y características. De hecho, si extendemos este argumento y lo ampliamos a la categoría de ser vivo no humano, es posible rastrear la emergencia de la comunicación desde la aparición misma de la vida.

Al respecto, en este texto nos proponemos reflexionar sobre el fundamento biológico de la comunicación y apuntar así a grandes rasgos a sus características, desde un escenario diferenciado por especies que permita inferir una posible relación entre la evolución de la vida biológica y la evolución de la comunicación. Aunque tamaña empresa, aún por construir, no será desarrollada aquí, intentaremos 
esbozar una hipótesis al respecto en aras de dar forma a nuestro argumento.

Para llevar a buen puerto esta tarea será necesario auxiliarse de los principales postulados de la biología evolutiva, ${ }^{2}$ así como de los de la biosemiótica, ambos soportes epistemológicos de la tesis que aquí se ensaya. Sin embargo, en la medida en que esto implica una modificación importante en la manera de entender al fenómeno comunicativo, será necesario también buscar el apoyo de la fenomenología ${ }^{3}$ de la experiencia, de donde bebe directamente nuestra propuesta de concepto de comunicación como comportamiento expre-

${ }^{2} \mathrm{La}$ biología evolutiva es aquella rama de la biología que se implica en una explicación del funcionamiento de la vida desde una perspectiva evolutiva. Nace del legado de Darwin sobre la evolución y postula a la selección natural en sus diferentes niveles como el aspecto más determinante de la evolución. Así mismo plantea a la relación de adaptación como un mecanismo de la sobrevivencia, soportado en los niveles de agencia, eficiencia y alcance de la selección. Para una mayor información se recomienda consultar la obra de Stephen Jay Gould, La estructura de la Teoría de la Evolución.

${ }^{3} \mathrm{La}$ fenomenología de la percepción es una rama de la fenomenología que defiende la configuración del conocimiento a partir de la experiencia situada en el cuerpo. Se le debe su desarrollo y consolidación a Merleau-Ponty, quien realiza una distinción esencial con respecto a la fenomenología trascendental de Husserl, de donde parte. Para una mayor comprensión se recomienda consultar la obra del autor, referida en la bibliografía de este trabajo. sivo, el cual a su vez se basa en los postulados del enactismo y la neurobiología. ${ }^{4}$

El trabajo estará estructurado en dos grandes apartados, el primero de los cuales se enfocará en insertar el concepto de comunicación que aquí se defiende como comportamiento y acto expresivo, rescatando así una reflexión sobre los umbrales mínimo, medio y máximo de la comunicación que hemos realizado en otros trabajos y que consideramos constituye un marco propicio para explicar a la comunicación como comportamiento expresivo. Esto último será materia del segundo apartado. Por eso en este apartado también,

${ }^{4} \mathrm{El}$ enactismo o enactivismo se inscribe en la corriente de pensamiento de la llamada Nueva Ciencia Cognitiva. Se enfoca en el estudio de los procesos de cognición y postula a grandes rasgos que la cognición no se da por medio de conceptos ni representaciones lógicas, sino en función de una serie de mecanismos físicos, químicos, genéticos, sensoriales, afectivos e intelectivos desde los cuales se construye información sobre el mundo y el sí mismo. Se soportan en la teoría de la autopoiesis de Maturana y Varela, pero la trascienden. Su concepto de información como algo que se construye en tanto no está dado, hace emerger una lógica fenomenológica del conocimiento. Para mayor información se recomienda consultar la obra de Di Paolo, referida en la bibliografía de este trabajo. En cuanto a la neurobiología, es una rama de la neurociencia que se inserta en los postulados de la biología evolutiva. En síntesis plantea que la consciencia es un constructo cerebral que se encuentra implicado necesariamente en el cuerpo. Su exponente más representativo es Antonio Damasio y se recomienda consultar su obra para mayor información. 
nos abocaremos a perfilar una tipología de la comunicación como acto y comportamiento expresivo que permita organizar las diferentes modalidades de comunicación que existen en función de la diversidad de organismos vivos que la ejercen, lo que a su vez planteará la posibilidad de definir de manera general sus características y los modos de operación que adquiere la comunicación a partir de ellas.

\section{LA COMUNICACIÓN COMO ACTO Y COMPORTAMIENTO EXPRESIVO}

Para comenzar a desarrollar este apartado se debe centrar la atención en el concepto de comportamiento y el concepto de expresión. Comenzaremos con el de expresión que es según se indica en el Diccionario de Filosofía de Ferrater Mora (1964), la forma subjetiva que adquiere un contenido (p. 626) -entiéndase significado-, el cual es fruto de una vivencia (p. 647).

Desde esta postura filosófica la expresión no solo siempre es subjetiva sino que posee un contenido que está anclado en el significado de la vivencia. Toda expresión es así resultado de una experiencia que se vive y toma forma de significado a partir de ella. A partir de estas directrices, derivar la expresión como comunicación es posible si se entiende a la expresión como una forma del decir propio
Vivian Romeu

del individuo que (se) expresa. Así, toda expresión comunica, en tanto "dice".

Una expresión, en primer lugar, "dice" algo, y ese algo — su contenido — no es ajeno al individuo que (se) expresa. La razón de ello hay que encontrarla en que lo que "decimos" ya que se configura a través de referentes de sentido que se construyen justamente a partir de la interacción que un individuo tiene con su entorno. Hasta ahí nada nuevo. Por ello, lo dicho siempre es manifestación o resultado del entramado de representaciones desde los cuales conformamos nuestro sentido de la realidad, sea que se trate de la realidad física, la realidad social e incluso la simbólica-cultural. Por ello, en segundo lugar, el hecho que una expresión "diga" siempre "dice" algo de nosotros. No se trata necesariamente de un decir sincero u honesto, sino de un "decir" que evidencia el vínculo subjetivo-experiencial desde donde se fragua su contenido, e incluso su forma. Este "decir" algo de nosotros que la expresión recrea como un "sacar afuera", es una especie de proyección del sí mismo que se activa en función de intereses y motivaciones concretas y circunstanciales.

De esta manera, queda claro que toda expresión visibiliza una relación entre el ser que (se) expresa y aquello a propósito de lo cual lo hace. Esta relación, que hemos llamado en 
otros trabajos, de socialidad, ${ }^{5}$ tiene un carácter implicativo y en ese sentido es insoslayable una vez que la expresión se configura como tal. Y es que si bien la expresión deviene una respuesta a aquello que la hace existir, no es menos cierto que puede no configurarse. $\mathrm{O}$ sea, si alguien nos pregunta la hora no tenemos necesariamente que responder. Podemos hacerlo o no. En ese sentido, la expresión despliega su naturaleza implicativa toda vez que respondemos mediante ella a aquello por lo cual nos sentimos o pensamos conminados a expresar(nos).

Entendido esto, es necesario enfatizar que toda expresión, en tanto subjetiva, depende de las capacidades, habilidades y competencias perceptivo-cognitivas y expresivas del individuo, ya que para expresar(se) hace falta poder y saber hacerlo, además de tener qué decir. De esta manera, poder "decir" implica

${ }^{5} \mathrm{El}$ concepto de socialidad lo hemos adaptado del concepto de sociabilidad de George Simmel (2002; 2014), a partir del cual el sociólogo alemán reconoce la existencia de relaciones sociales que se gestan a través de lo que él llama formas de socialización. Estas formas de socialización oscilan entre aquellas que están regidas por el poder y las que no. Debido a que Simmel reserva el término de sociabilidad para hablar de estas últimas, para no confundir, aquí se propone, tomando como base la conceptualización de Simmel, hablar de socialidad como un término mucho más genérico en cuanto resume todos los tipos de relaciones sociales que se instalan entre los individuos a través de las formas de socialización.
Vivian Romeu

contar con el equipamiento orgánico necesario para cada expresión (esto es lo que entendemos por capacidad), mientras que saber "decir" supone contar con los recursos para ello (a esto le llamamos competencia). En cuanto a la habilidad es el entrenamiento o expertise de una o varias capacidades (Hontanga, 1994).

Cuando estos aspectos se ponen en marcha para configurar la expresión, se despliega lo que hemos llamado una actuación expresiva. Dicha actuación no es otra cosa que una acción significativa que se gesta en el orden del "decir", o lo que es lo mismo: una conducta o comportamiento a través de la cual se “dice" (Romeu, 2017).

Es así que podemos conceptualizar la comunicación como comportamiento expresivo donde dicha acción/actuación no es más que la respuesta que da un individuo a un estímulo por medio de su expresión o su "decir". Esto a su vez implica pensar al acto expresivo como aquel que señala, indica, apunta o muestra un significado a propósito de algo, y no — nótese — necesariamente para alguien.

Como se puede ver, esta conclusión deja sin sentido la idea de que la comunicación indica o apunta necesariamente algo a otro para enfocar lo comunicativo al hecho de indicar algo ante o por el otro — que no es más 
que eso que le ha estimulado-, en función de la relevancia significativa que el individuo otorga al estímulo en términos de sus intereses y motivaciones, sean estos conscientes o no (Damasio, 2015). Así, la relevancia significativa se instituye como una categoría relacional, ya que algo es relevante para un individuo en función de sus condiciones biológicas, psicológicas, simbólicas, sociales, culturales y en general espacio-temporales concretas (según el individuo del que se trate). Por ello, fraguamos una conceptualización de estímulo desde un punto de vista no mecanicista, sino fenomenológico. Solo lo que tiene relevancia significativa para un individuo puede movilizar su respuesta expresiva, aun y cuando los individuos tengan la posibilidad de activarla o no.

Desde esta perspectiva, la conceptualización que aquí se hace del estímulo se inserta en los postulados de la semiótica pragmática y particularmente en los de la biosemiótica, ${ }^{6}$ lo

'La semiótica pragmática hunde raíces en la teoría general de los signos propuesta por Charles Peirce. A grandes rasgos entiende a la semiótica como una lógica, una epistemología, de manera que hace recaer el peso de la configuración cognitiva en el individuo. Derivada de ella, la biosemiótica es una rama de la biología teórica que anclada en los postulados peircianos abona a la comprensión de los sistemas vivos como sistemas de interpretación. Para una mayor comprensión de este particular se recomienda consultar la obra de Santilli referida en la bibliografía de este trabajo. que se vincula con las posturas fenomenológicas sobre la percepción y la experiencia. El estímulo, tal cual lo definimos aquí, constituye una instancia de interpelación para el individuo. Esto significa que sólo hay estímulo en la medida en que el individuo se siente o se piensa interpelado por algo, por algún motivo. Es decir, los estímulos — como los signosno existen en la realidad, sino que son construidos en nuestra mente y se movilizan como algo que nos interpela perceptivamente. Esta interpelación puede ser consciente o no, pero siempre es implicativa, es decir, no se puede dejar de responder a ella, lo que no quiere decir que la respuesta deba ser siempre expresiva o comunicativa (ésta es una más entre otras).

Así las cosas, una respuesta expresiva demanda una implicación del individuo con respecto a aquello que percibe como un estímulo, de manera que éste no resulta eludible, ya sea por un interés o motivación, consciente o no. Si el interés es inconsciente, se actúa de manera programada o predeterminada, a través de conductas estereotipadas y rígidas que aunque son propias de todos los seres vivos, son exclusivas de aquellos sin consciencia e incluso con un grado muy bajo de ella. Si el interés es consciente, se dan actuaciones signadas por la voluntad y en ese sentido pueden ser creativas, lo cual es característico de aque- 
llos organismos vivos con posibilidad de elegir sus comportamientos, aun y cuando el abanico de estas posibilidades oscile entre muy primitivo y restringido a muy diverso y amplio, como efectivamente sucede.

Sin duda alguna, esta diversidad y amplitud de comportamientos se halla estrechamente relacionada con la capacidad, habilidad y competencia del individuo para configurar su actividad perceptivo-cognitiva y expresiva; de ahí la variabilidad de respuestas que un individuo activa ante un estímulo determinado, en función de la manera en que lo perciba y la forma expresiva que emplee y/o seleccione para enfrentarlo. Esa es la razón por la que la comunicación debe conceptualizarse como una respuesta expresiva propia del individuo en su experiencia vital, que tiene lugar —en dependencia de las capacidades, habilidades y competencias del mismo- mediante el uso expresivo de la información que éste construye como parte de sus procesos de adaptación y sobrevivencia en la gestión de su vida (Romeu, 2016).

Si el individuo tiene la capacidad para expresarse por voluntad propia, como sucede fundamentalmente con los seres humanos, el acto expresivo adquiere carácter intencional y posibilita, además, la producción de actos expresivos de intervención que, en tanto tales, hacen emerger comportamientos de agencia. En cambio, cuando se trata de individuos que no tienen capacidad de expresar(se) volitivamente, el acto expresivo se torna no intencional y deriva en comportamientos significativos que son simples actuaciones performativas. En ninguno de ambos casos los actos expresivos pierden o cancelan su naturaleza implicativa, pues esta no depende de las intenciones o voluntades. Con esto, damos paso a una conceptualización de la comunicación que no se reduce al escenario simbólico e incluso al del lenguaje social, 7 mucho menos se explica a partir de la presencia de ambos elementos.

Asumiendo esta perspectiva, la comunicación es posible —al menos desde su umbral más bajo- gracias a la mera actuación expresiva que ya es un modo de relación/implicación con el otro-entorno que funciona como estímulo, pues de otro modo no tendría lugar. Y desde su umbral más alto, la comunicación tiene lugar como instancia de intervención a través del despliegue, intencional por más se-

${ }^{7}$ Cuando se habla de escenario simbólico aquí se hace referencia a la plataforma de valores, significados, costumbres y tradiciones inscritos en la cultura. Y por lenguaje social entendemos un sistema de representaciones que es construido a partir de la relación convencional, arbitraria y colectiva con que un evento u objeto es significado al interior de una determinada cultura y que permite la puesta en común de referentes. 
ñas, de la agencialidad del individuo. ${ }^{8}$ En función de esta variabilidad, a continuación se reseña de modo muy breve y esquemático las características del "decir" de los individuos vivos, segmentando a éstos en función de sus capacidades, habilidades y competencias perceptivo-cognitivas y expresivas. Para ello se ha empleado el criterio de posesión o no de cerebro, el cual permite a su vez dividir en una primera instancia a los individuos en sentientes o no sentientes, y posteriormente en poseedores o no de intención, lo cual depende esencialmente del grado de consciencia de sus actos y comportamientos. Veamos.

\section{LOS UMBRALES DE LA COMUNICA- CIÓN: MÍNIMO, MEDIO Y MÁXIMO}

La conceptualización que hemos venido desarrollando en torno a la comunicación como comportamiento expresivo ha permitido esbozar la idea de que no es un comportamiento exclusivo de los seres humanos. Al ser los comportamientos actividades que cualquier

${ }^{8} \mathrm{El}$ concepto de agencia lo hemos tomado aquí desde los postulados de la sociología estructural-constructivista de Pierre Bourdieu para quien la agencia es la capacidad de acción de un individuo a partir de intenciones o inercias intencionales vinculadas a su posición en el orden social. También desde la teoría de la agencia de Deleuze, la agencialidad es la acción que desarrollan conscientemente los actores sociales. Nosotros hemos extendido y adaptado el concepto a todas las especies con volición. ser vivo realiza para mantener y desarrollar su vida en relación con su entorno, respondiendo a él y —en su caso— ${ }^{9}$ modificándolo (Galarsi, Medina, Ledezma y Zanin, 2011, p. 99), toda respuesta a estímulos provenientes del entorno resultan comportamientos y pueden ser tanto innatos (estereotipados, rígidos y predeterminados en tanto carentes de reatroalimentación externa) como aprendidos (dados por habituación, asociación e influjo social). ${ }^{10}$

En el caso del comportamiento expresivo que es el que aquí ocupa, se diferencia internamente de otros porque se da en el orden del “decir". Esto significa que el comportamiento tiene una impronta expresiva que coloca a la expresión en el espacio público, es decir, en el

${ }^{9}$ Las cursivas son nuestras, puesto que la cita está inserta en un apartado que hace referencia a los seres humanos solamente, que en buena medida, tienen la capacidad de modificar el ambiente con su comportamiento.

${ }^{10}$ Esta clasificación la hemos obtenido del trabajo de Galarsi, Medina, Ledezma y Zanin (2011, pp. 95-97), que señalan que los comportamientos se organizan por su grado de complejidad. Así, a grandes rasgos, el de habituación permite aprender a ignorar un estímulo repetido, insensibilizando al organismo ante él; le sigue el de asociación donde el aprendizaje ocurre vía la experiencia, a través del método del ensayo y error (aquí también tiene lugar el aprendizaje a través de la influencia filial que tiene una impronta de pertenencia), y por último, el más complejo de todos, es el que se da a través de la influencia social donde un individuo ajeno a la "familia" logra influir en el aprendizaje de otro. 
espacio ajeno al Yo, el del otro. Por eso, con independencia de la clasificación tradicional de los comportamientos que señala Galarsi, Medina, Ledezma y Zanin (2011) —divididos en públicos o privados, conscientes o inconscientes, voluntarios o involuntarios, usuales o inusuales, sociales e individuales-, el comportamiento expresivo se soporta en el acto de "decir" que es un acto de sentido que se hace para indicar, mostrar, señalar, apuntar... Sin embargo, todo comportamiento (incluyendo el expresivo) obedece al uso que haga un determinado individuo de la información que logra construir vía la interpretación (Di Paolo, 2013; Varela, 2005) a partir de sus capacidades, habilidades y competencias perceptivocognitivas (Damasio, 2015), lo que nos hace pensar que la materia prima de todo comportamiento es la información y, en el caso particular de la comunicación, su uso expresivo es lo propiamente comunicativo (Romeu, 2016).

Teniendo esto en cuenta, vale la pena aclarar que los individuos de todas las especies tienen comportamientos, de manera que puede decirse que usan la información para gestionar su vida y sobrevivencia; y en el caso de los comportamientos expresivos, deben además- usar expresivamente dicha información, lo que depende tanto de sus capacidades, habilidades y competencias percepti-

\section{Vivian Romeu}

vas-cognitivas (implicadas en la construcción de información) como de las capacidades, habilidades y competencias expresivas (implicadas en el uso de dicha información). Es esto lo que nos permite sostener que la comunicación tiene varios niveles o umbrales, mismos que no se articulan a través de un criterio de número, tal cual se hace ahora en el campo de estudios de la comunicación (nivel interpersonal, grupal, organizacional, social y mediático), sino más bien en función del grado de complejidad del acto expresivo en sí mismo.

Por ejemplo, el intercambio de información que se da en las hormigas y las abejas tienen un carácter biosocial, a diferencia de otras especies más psicosociales como sucede con algunas aves y mamíferos, u otras de carácter ciertamente simbólico propias de algunos mamíferos superiores, pero sobre todo desarrolladas en un grado superlativo en los seres humanos. La diferencia en la naturaleza de estos comportamientos comunicativos reside básicamente en la capacidad mental de estos individuos. Las hormigas no poseen un gran cerebro (tiene pocas neuronas y poquísimas sinapsis) por lo que su actividad cognitiva suele estar programada neuralmente, es decir, determinada, configurando así esquemas de comportamiento mayormente innatos, es decir, instintivos, incluyendo los expresivos. 
Por eso sus actuaciones expresivas están acotadas a una serie de ocurrencias esterotipadas y no intencionales, que son "comprensibles" también por otras hormigas de la misma especie en tanto poseen lenguaje social, aunque sea muy primitivo e innato. En individuos solitarios como los hongos y las bacterias por ejemplo, sus actuaciones expresivas son, además de esterotipadas, no compartidas, lo que implica la ausencia de lenguaje social.

En el caso de mamíferos como las ratas, se sabe que aunque no poseen un gran cerebro, son animales bastante inteligentes por lo que su actividad cognitiva, además de utilizar los recursos innatos con los que cuenta, se enfoca en agenciarse otro tipo de recursos vía el aprendizaje dado su desarrollo psicosocial, aumentando así la gama de sus comportamientos. Sin embargo, la pequeña memoria de la rata hace imposible la perdurabilidad de estos aprendizajes, de manera que aunque puedan tener actuaciones expresivas no estereotipadas, éstas deben ser siempre convocadas para cada ocasión. Mención especial merecen los perros, y en general los animales domésticos, los cuales, al igual que las ratas pueden aprender cosas nuevas, pero a diferencia de aquellas son capaces de recordar mucha mayor cantidad de información y, además, comparten un leguaje social bastante eficaz
Vivian Romeu

que les permite gestionar su vida en colectivo, al igual que los mamíferos superiores.

En cuanto al carácter simbólico de los comportamientos, mayormente atribuidos a los seres humanos (aunque hay evidencia de esto también en algunos de los mamíferos superiores) se ha de decir que en todos estos animales, la capacidad cerebral es más grande y aloja una mayor memoria (según Sagan, 2016, la del ser humano es al parecer superior en varios millones de bites). Por eso, a los comportamientos biopsicosociales, también propios de estas especies, se suma el comportamiento simbólico que deriva de la manera en que las representaciones de la realidad se configuran al margen de las sensaciones y las emociones a las que van a asociadas y que expresivamente operan a través de un lenguaje social mucho más rico y amplio en el sentido de que no precisa de una convocatoria referencial en el presente para referir las cosas del mundo.

Así, mientras que el comportamiento no simbólico se define por su predeterminación instintiva, en el comportamiento simbólico entra a jugar la facultad de la razón que, como se ha dicho, también presenta grados a través de los cuales se diferencia. Uno de estos criterios diferenciadores lo constituye sin duda la presencia de lenguaje verbal articulado que 
poseen los humanos, quien es el animal racional por excelencia en cuanto a que es el que mayor uso le ha dado a su racionalidad, acumulando este tipo de experiencias cogitativas o intelectivas en lo que conocemos como cultura, la cual a su vez funciona como un depósito de memoria extendida o externa, y por tanto de aprendizaje perenne.

Bajo esta escala de gradación diferenciada que se ha tratado de esbozar a través de estos ejemplos, queda claro que los comportamientos de los individuos poseen una naturaleza evolutiva en función de las capacidades de éste y los retos a los que debe hacer frente. Ello puede conducir o no a nuevas capacidades, o a la modificación parcial de alguna, lo que también tendrá un impacto potencialmente en su expresión ya que la transformación de las capacidades siempre trae asociada evolutivamente una transformación en las habilidades y competencias, lo que implica a su vez una transformación en la actividad perceptivacognitiva de los individuos y eventualmente en la expresiva también.

Según los postulados del enactismo (Di Paolo, 2013), hay tres grandes vías o formas en que opera la actividad perceptivo-cognitiva de un individuo que no es más que la actividad desplegada para construir información o conocimiento sobre lo que le rodea, e incluso, en algunos casos, sobre su sí mismo. Está así la vía metabólica donde la información es construida sin que medien operaciones cognitivas complejas debido a que el individuo actúa perceptual y cognitivamente de forma programada en función de sus necesidades vitales básicas (por ejemplo, las bacterias tienen un equipamiento fisiológico que le permite detectar y reaccionar a la presencia de moléculas de azúcar a través de las cuales se alimenta); está también la vía sensorial, donde el conocimiento o información se construye a partir de los órganos sensoriales, muy vinculados a las sensaciones y emociones activadas mentalmente por el individuo (por ejemplo, cuando olemos un aroma a comida que nos apetece). Por último, está la vía racional o intelectiva a partir de la cual los humanos construimos información del mundo operando conceptos para gestar conocimiento sobre ella (Di Paolo, 2013).

Esta sencilla división por niveles o vías a través de las cuales opera la actividad cognitiva permite dividir a su vez en dos la información que se puede construir a partir de ella: un tipo de información que es simbólica (operada cognitivamente por la vía intelectiva) y otra no simbólica (operadas por las vías metabólica y sensible). Esto conlleva a afirmar que la comunicación tanto en términos no simbólicos 
como simbólicos, se puede agrupar para su estudio en dos grandes tipos: la comunicación no simbólica y la comunicación simbólica, respectivamente (Romeu, 2016).

Por comunicación no simbólica, referimos a aquella comunicación que se da a través de actos expresivos que no involucran al lenguaje social —simbólico por naturaleza, aunque ya vimos que se da a través de grados diferenciadores - y se coloca por lo tanto en el umbral inferior de la comunicación el cual presenta limitaciones expresivas para el individuo toda vez que no puede, en tanto no lo posee, hacer uso de un lenguaje común o social, ${ }^{11}$ cancelando así la posibilidad de hacerse entender ante otros de su misma u otra especie, y eventualmente impidiendo su interven-

\footnotetext{
${ }^{11} \mathrm{~A}$ este lenguaje no social lo he llamado por oposición como lenguaje individual, entendiendo por ello un sistema de representación mental propio, derivado de las experiencias de los individuos (unas predeterminadas, otras aprendidas) que no está estructurado socialmente, en tanto se halla atado a las estructuras mentales de cada organismo, dando lugar a representaciones mentales individuales, es decir, no compartidas. Según el enactismo, todos los organismos vivos poseen este tipo de lenguaje y en la medida en que sus capacidades, habilidades y competencias lo permitan (como sucede con el caso del bebé e incluso algunos animales domésticos como perros y gatos), los individuos po-drán adoptar y aprender el lenguaje social, que es funcional para organismos que deben gestionar su vida de manera conjunta, es decir, en grupos o sociedades.
}

ción con respecto a este otro en el sentido expresivo.

Así entendida, la comunicación no simbólica es propia, pero no exclusiva, de los llamados individuos solitarios, que son organismos que no necesitan de otros para sobrevivir puesto que garantizan por sí solos su alimentación y reproducción (plantas, hongos, bacterias, protistas y algunos animales como las esponjas y los corales). Al no precisar de lenguaje social y tampoco simbólico gestionan su vida y su actuación expresiva a partir de la primitiva estructura mental con la que vienen equipados; de esa manera su interacción con el entorno es programada, predeterminada $y$ no intencional que es lo que llamamos comunicación no simbólica autogestiva (Romeu, 2016).

El otro subtipo de comunicación no simbólica es la que se caracteriza por la manera sensorial en que se construye la información. La hemos nombrado como comunicación sensible y está presente en organismos vivos sentientes y con algún grado de consciencia en tanto cuentan con sistema nervioso central; de ahí que en función de su actividad nerviosa y capacidad cerebral, despliegan una estructura mental cuyas relaciones de sentido se activan a través de las condiciones de sensibilidad que 
su aparato sensorial le provee. ${ }^{12}$ Estas condiciones de sensibilidad oscilan en una gama de sensaciones que va del placer al displacer, en tanto estos extremos constituyen el mínimo de sensaciones que se registran en las actuaciones sensibles. Desde la comunicación no simbólica, este subtipo de comunicación es también autogestiva (en función de las necesidades biológicas del sí mismo) y se define por la predeterminación de sus comportamientos. Pero la comunicación sensible también puede ser heterogestiva (en función de las necesidades biológicas o de otro tipo con respecto a los otros), insertándose así en la comunicación simbólica, aunque de esto ha-blaremos más adelante.

$\mathrm{Al}$ igual que sucede en la comunicación programada, en la comunicación sensible no simbólica no se da un uso expresivo de la información que no es reflexivo ni lingüístico, lo que cancela de inmediato la posibilidad de referirnos a los soportes y materias expresivas como medio y mensaje respectivamente, mucho menos hablar de intención expresiva o

\footnotetext{
${ }^{12}$ Los insectos y algunos mamíferos, por ejemplo, tienen muy desarrollado el sentido del olfato, en cambio los peces tienen el sentido del oído más aguzado. Para los seres humanos y los primates en general el sentido más importante es la vista, mientras que los murciélagos hacen del oído y del tacto sus sentidos preponderantes. Por supuesto, lo anterior no invalida el uso de otros sentidos, en el caso de que lo posean.
}

entendimiento. La comunicación no simbólica y sus dos subtipos (programada y sensible), son comunicaciones intencionadas (ojo, no confundir con intencionales), o sea, derivadas del despliegue de la intencionalidad del individuo a la manera de un impulso de vida, o si se prefiere, de una reacción orgánica y/o sensible (según sea programada o sensible, respectivamente) ante el entorno. Pero la comunicación sensible, a diferencia de la programada, gesta una actuación expresiva de tipo perfomáticoexistencial que se diferencia de la actuación programada en la medida en que no está determinada genética o metabólicamente por procesos físico-químicos organizados para mantener el estado vital; el acto expresivo performático-existencial se da siempre en forma de reacción sensible al ambiente. En ese sentido, la comunicación sensible posibilita la emergencia de un acto expresivo que da cuenta del estado sensible del organismo en un determinado momento, como respuesta expresiva a un estímulo cualquiera. Esto es posible ya que las sensaciones se configuran como experiencias de los organismos con algún grado de consciencia. ${ }^{13}$

\footnotetext{
${ }^{13}$ Los insectos, por lo general, no son seres sentientes; más bien reaccionan a estímulos molestos o apetitivos, pero no sienten dolor: una lagartija, por ejemplo, que se le corta el rabo no siente dolor, pero un perro o un
} 
Lo anterior permite definir la comunicación sensible en organismos poco desarrollados a nivel mental como un subtipo de comunicación no simbólica que es ejecutada por individuos sentientes equipados con diferentes aparatos de sensibilidad, recursos sensibles y distintos grados de consciencia para moldear sus actuaciones expresivas. Si el individuo posee un alto grado de consciencia es muy probable que emplee la comunicación sensible tanto desde una perspectiva no simbólica (autogestiva) como desde una simbólica (heterogestiva). En ese sentido, en su variante simbólica, la comunicación sensible se configura consciente e intencionalmente con respecto al sí mismo y al otro en tanto las sensaciones, emociones y afectos se insertan también en la cultura desde donde se suelen regular. Bajo esta premisa, el criterio de distinción más fuerte entre la comunicación simbólica y no simbólica, sobre todo para el caso de la comunicación sensible que se inserta en ambos tipos, es la posibilidad o no de intención.

Ya hemos comentado cómo intención e intencionalidad son dos aspectos del comportamiento de los organismos vivos cuya diferencia estriba precisamente en la presencia o no de intereses o motivaciones conscientes en

ave sí, lo que se debe al diferente nivel de consciencia de estos animales. sus actuaciones expresivas. Por eso, la presencia de intención o motivación consciente permite comportamientos de agencia en tanto configurados alrededor de la consecución de un fin, previa y conscientemente establecido desde el punto de vista mental. Esto marca claramente la diferencia con la comunicación no simbólica que, con base en la ausencia consciente de interés, da por resultado una actuación expresiva de tipo performático-existencial, cuando no programada.

Pero la intención, aunque siempre consciente, no opera de la misma manera en todos los organismos, lo que depende de sus grados de consciencia. Hay consciencia de entorno, llamada perceptiva o de sí y consciencia autorreflexiva. Los organismos que tienen solamente una conciencia de entorno se definen como seres no pensantes (entendiendo al pensamiento desde una lógica racional) aunque poseen una inteligencia práctica que les permite aprender y resolver problemas poco complejos (Prieto, 2012). ${ }^{14}$ Estos organismos desarrollan lo que hemos llamado una intención

\footnotetext{
${ }^{14}$ En realidad, esta clasificación queda aun entrampada en el debate sobre la memoria, pues para muchos autores el problema no está en la capacidad de razón (irracionales $v s$ racionales) sino en la capacidad de memoria que es lo que distingue a los humanos del resto de los animales, aun los más inteligentes. Para mayor información consultar el libro de Sagan referido en la bibliografía de este trabajo.
} 
concreta o puntual, que también puede nombrarse como instrumental, enfocada en la solución de problemas concretos y acotados a la realidad fáctica que la provoca.

En cambio, los organismos con consciencia autorreflexiva (cuyo máximo exponente somos los humanos) son individuos pensantes que pueden por ello desarrollar, además, una inteligencia de tipo abstracto, configurando así intenciones abstractas o especulativas, estrechamente asociadas tanto a las características orgánicas del cerebro humano como a la enorme capacidad de memoria $y$, sobre todo a la presencia del lenguaje verbal articulado. ${ }^{15}$ Esto

${ }^{15} \mathrm{El}$ lenguaje verbal permite describir y explicar a otros lenguajes y a sí mismo, por ello posibilita la emergencia de un sistema (que no conjunto) de representaciones y referencias articuladas/estructuradas entre sí, desde el cual se amplifican las conexiones entre los distintos elementos de diferentes lenguajes propiciando así la aparición de un pensamiento más complejo en tanto se permite dejar de estar al servicio de las situaciones inmediatas en aras de situaciones pasadas y sobre todo, futuras. La facultad de nombrar más allá de los escenarios de ocurrencia de las cosas en el presente es exclusiva del lenguaje verbal articulado (lo que no resulta menor si se tiene en cuenta que el ser humano ha creado además tecnología que permite transmitir culturalmente dicho lenguaje al margen de la inmediatez), y aunque ello puede resultar la base de muchos otros lenguajes (el de los sordomudos, por ejemplo), en el caso de los animales - aun los más inteligentescarecen de capacidad cerebral para pensar el futuro a largo plazo por lo que su lenguaje se reduce a nombrar y comprender el mundo tal cual lo perciben, y con escasa relación entre señales y representaciones. Por ello el alcance de su intención especulativa se reduciría último es lo que posibilita la articulación no solo de intenciones sino también de sensaciones y representaciones mentales complejas por medio de procesos de abstracción que se dan a través de la articulación entre ideas (Melgar, 2000), que es la fuente de la imaginación vía el muy desarrollado sentido que los humanos tenemos de las anticipaciones a futuro ${ }^{16}$.

Queda claro entonces que las actuaciones expresivas dentro de la comunicación simbólica se articulan bajo la forma de intervención desde la intención de intervenir/modificar al otro-entorno. Esto, por supuesto, no es exclusivo de la especie humana, pero ciertamente los humanos parecen ser los más exitosos en ello. Vinculados al sistema de representaciones que le da sentido y referencia específica socialmente compartida a la realidad de las cosas del mundo material, social e imaginado, el mundo especulativo del individuo humano

\footnotetext{
- en el caso de que la puedan activar- a la exploración del mundo en el presente.

${ }^{16} \mathrm{La}$ voluntad o intención, cuando está atada a lo inmediato y a lo sensorial-emotivo-afectivo se despliega de forma concreta, cuya naturaleza instrumental permite definirla como instintiva o determinada. Sin embargo, cuando la voluntad se halla asociada a lo mediato (situación no presente) y a lo conceptual (el puro pensar: relación idea-idea), se trata de una intención especulativa a partir de su naturaleza abstracta o conceptual, en tanto se vincula siempre con el sistema de representaciones simbólicas de un organismo que se guardan en su memoria para ser activadas en momentos concretos de su ciclo de vida.
} 
tiene mayor alcance y complejidad que el de los individuos de otras especies en cuanto a la manipulación de la voluntad a través de la agencialidad. Así, a diferentes grados de intelectividad o racionalidad (en dependencia de las características orgánicas de sus cerebros y el grado de capacidad, habilidad y competencias de los mismos), habrá diferentes grados de complejidad en la actuación expresiva de intervención.

Justo en este umbral de la agencialidad interventiva se puede situar el umbral máximo de la comunicación dado que el grado de consciencia en la incidencia de las actuaciones expresivas de los individuos con respecto al otro-entorno, permite gestar intervenciones de diferente duración. Por ello las intervenciones que tienden a afectar de manera más o menos perenne el estado de cosas de una realidad (como aquellas propias de los seres humanos) pasan a formar parte de los procesos de producción y reproducción de la cultura y con ello del acervo de información de los seres humanos, garantizando así su uso colectivo. Es esto y no otra cosa, lo que ha de permitir comprender la trascendencia de la comunicación en el seno de la vida personal, social y/o cultural de los seres humanos y también de otras especies, obligándonos a mirar más allá de nuestras narices antropomórfi- cas. Quizá, teleológicamente incluso, es hacia donde debemos enfocar nuestros esfuerzos como investigadores y profesionales de la comunicación desde una perspectiva biológica y evolutiva pues solo así se podrá ver la comunicación en toda su dimensión: nada más y nada menos que como un comportamiento de tipo expresivo.

\section{CONCLUSIONES}

Como se habrá podido apreciar, lo dicho hasta el momento señala la posibilidad de una mirada otra sobre la comunicación, la cual, sin dudas, permite un mayor alcance heurístico. A propósito de ello hemos situado el objeto de estudio de la comunicación en el uso expresivo de la información que los individuos construyen en su inevitable interacción con el entorno en el que se insertan, pues de ello se derivan o configuran los actos expresivos por medio de los cuales un individuo "dice", que es lo que conforma el rico y disímil abanico de sus comportamientos expresivos.

He ahí que hemos situado también la diferencia entre los comportamientos comunicativos de humanos y animales, desde una perspectiva de grado y no de esencia, lo que se aviene a los postulados básicos de la biología evolutiva donde insertamos nuestra propuesta. Dicha propuesta reconoce solo dos tipos de 
comunicación: la simbólica y la no simbólica, y a partir de ellas cuatro subtipos en estricto orden de menor a mayor complejidad: por una parte, la comunicación programada y la comunicación performática-existencial (donde se inserta la comunicación sensible no simbólica), y por la otra, la comunicación enunciativa de intención concreta y especulativa, respectivamente. Lo que hoy el campo académico de los estudios sobre la comunicación acepta como tipos de comunicación (intercultural, política, mediática, artística, educativa, publicitaria, y todas sus matrices: audiovisual, lingüística, espacial, intersubjetiva, social, etc.) son en realidad modalidades operativas y ámbitos comunicativos, respectivamente, de cada uno de los tipos y subtipos aquí propuestos.

En ese sentido, parece fácil advertir cómo la comunicación es estudiada hoy en día prácticamente desde un paradigma humano, simbólico e intencional que restringe su propia naturaleza de comportamiento expresivo. Con la propuesta que aquí se ha esbozado buscamos ampliar el marco de situaciones biológicas, sociales, psicológicas, personales, intersubjetivas y culturales en las que la comunicación tiene algo que decir y de manera distintiva con respecto a otras disciplinas. Por ejemplo, la comunicación puede ganar para sí lo que en la biología se estudia ya como comuni- cación neuronal, celular, metabólica; también podría ocuparse de la comunicación animal y vegetal, ámbitos de estudio que hoy están en manos de los etólogos. De esa manera se tenderían puentes con disciplinas que se creen separadas de la comunicación, como la psicología y la biología. La necesidad de la transdisciplina desde la propuesta de la comunicación como comportamiento y acto expresivo resulta un imperativo teniendo en cuenta lo que aquí se ha esbozado.

No es menos cierto que el campo académico de la comunicación se ha caracterizado desde sus inicios por tratar de estudiar la sociedad, disputando con ello el ámbito de estudio por excelencia de la sociología. Desde estas directrices, la comunicación se entendió (y lamentablemente aún se entiende) como subsidiaria de la sociología pues a través del análisis de los medios masivos — configurados por mucho tiempo, y aún incluso, en el meollo del análisis social desde un punto de vista comunicativo- se pretendió explicar el funcionamiento de la sociedad y las relaciones sociales que la conforman. Para nosotros esto evidencia la usurpación inconsciente que ha hecho el campo académico de estudios sobre la comunicación en torno a un objeto de estudio que no le corresponde, y quizá la propuesta epistémico-conceptual que aquí se esboza pueda 
contribuir a reflexionar sobre ello y en particular sobre el estatuto pluridisciplinar de nuestro campo científico, dada la innegable naturaleza transdisciplinar de nuestro objeto de estudio.

Así, lo relevante de esta línea de trabajo entre comunicación y biología evolutiva es que desde ella se permite dar forma a la manera en que la comunicación ha acompañado el largo y complejo proceso evolutivo de las especies hasta nuestros días. Particularmente, en el tiempo presente, comprender la comunicación como un comportamiento implica a su vez pensar en las formas y contenidos que adquieren nuestros actos expresivos desde un punto de vista reflexivo y crítico, y no solo en torno a nosotros mismos como humanos, sino también con respecto a otras especies y el medioambiente en el que desarrollamos nuestra gestión vital, que en el caso de los seres humanos no solo debe entenderse desde el punto de vista natural o físico, sino también simbólico, social, político, económico, moral, etc. Esa es la razón por la que en el marco de una articulación exitosa entre comunicación y evolución es posible recrear escenarios de reflexividad científica que estratégicamente, incluso, nos permitan pensar la comunicación desde su enfoque teleológico; ese para qué que sigue dando vueltas sin encontrar sitio aún desde donde trazar desde una perspectiva ética y socialmente responsable la proyección de nuestras actuaciones expresivas pasadas, presentes y futuras. 


\section{FUENTES CONSULTADAS}

Damasio, A. (2015). El error de Descartes. Barcelona: Paidós Booket.

Di Paolo, E. (2013). "El enactivismo y la naturalización de la mente". En: Chico D.P. y Bedia M.G. (coords.). Nueva ciencia cognitiva. Hacia una teoría integral de la mente. Madrid: Plaza y Valdés. Recuperado de https://ezequieldipaolo.files.wordpress.com/2011/10/enactivismo_e2.pdf.

Ferrater Mora, J. (1964). Diccionario de Filosofía. Buenos Aires: Editorial Sudamericana.

Galarsi, M.F.; Medina, A.; Ledezma, C.; Zanin, L. (2011). "Comportamiento, historia y evolución”. En: Fundamentos en Humanidades. Universidad Nacional de San Luis, Argentina, año XII, núm. II, 24, 89-102. Recuperado de http://fundamentos.unsl.edu.ar/pdf/articulo-24-89.pdf.

Hontangas, P.M. (1994). "Ajuste de habilidades en el ámbito laboral”. En: Estudio de la congruencia de habilidades persona-puesto: aplicación de dos métodos alternativos. Tesis doctoral. Facultad de Psicología de la Universidad de Valencia.

Prieto, L. (2012). "Instinto, inteligencia y consciencia. A propósito de la cuestión de si es inteligente el conocimiento animal”. En: Manuel Oriol (ed.). Inteligencia y filosofía, 681-689. Madrid: Ediciones Morova. Recuperado de http://www.academia.edu/9729941/Instinto_inteligencia_y_conciencia_ y en http://philpapers.org/archive/HCTQUE.pdf.

Romeu, V. (2016). "Pensando a la comunicación y al fenómeno comunicativo". En: Anuario de Investigación de la Comunicación, CONEICC XXIII, 17-55. . (2017). El fenómeno comunicativo. Documento mimeografiado.

Sagan, C. (2016). Los dragones del Edén. Especulaciones sobre la evolución de la inteligencia humana. México: Paidós.

Simmel, G. (2002). Individualidades y formas sociales. Buenos Aires: Universidad de Quilmes. . (2014). Sociologia: estudios sobre las formas de socialización. México: Fondo de Cultura Económica.

Varela, F. (2005). Conocer. Barcelona: Gedisa. 